UMA ANÁLISE DOS FUNDAMENTOS DA ESCOLA SEM PARTIDO EM RELAÇÃO AO CURRÍCULO DE SOCIOLOGIA DO ENSINO MÉDIO

Guilherme Luiz Pereira Costa

Jucieude de Lucena Evangelista

Karlla Christine Araújo Souza

\title{
UMA ANÁLISE DOS FUNDAMENTOS DA “ESCOLA SEM PARTIDO” EM RELAÇÃO AO CURRÍCULO DE SOCIOLOGIA DO ENSINO MÉDIO
}

\author{
UN ANÁLISIS DE LOS FUNDAMENTOS DE LA "ESCOLA SEM PARTIDO" EN \\ RELACIÓN AL CURRÍCULO DE SOCIOLOGÍA EN LA ENSEÃNZA MEDIA
}

Guilherme Luiz Pereira Costa Jucieude de Lucena Evangelista

Karlla Christine Araújo Souza

\section{RESUMO}

Este trabalho trata de uma reflexão sobre o projeto Escola sem Partido a partir da perspectiva do ensino de Sociologia no ensino médio. Apesar desse projeto ainda não estar concretizado, sua iniciativa já demonstra uma perspectiva preocupante para a educação no Brasil. Sua proposição não representa nenhuma iniciativa no sentido de corrigir os problemas que afetam a educação no país. Uma das políticas de educação dos últimos anos consistia na valorização do professor como uma das estratégias para melhor a educação básica. Ao contrário disso, esse projeto não propõe qualquer valorização do professor, mas o fragiliza, pela criminalização da sua liberdade de pensamento e de expressão, além de estimular a intolerância. Nosso objetivo é avaliar as prováveis implicações desse projeto para o exercício do magistério. Tal projeto pode afetar profundamente a elaboração dos programas de disciplina, a composição dos conteúdos curriculares bem como sua abordagem, além da laboração e a escolha de material didático. A discussão é desenvolvida através da análise dos fundamentos do projeto Escola sem Partido, colocando-os em relação aos parâmetros que orientaram a proposta de currículo de Sociologia 
UMA ANÁLISE DOS FUNDAMENTOS DA ESCOLA SEM PARTIDO EM RELAÇÃO AO CURRÍCULO DE SOCIOLOGIA DO ENSINO MÉDIO

Guilherme Luiz Pereira Costa

Jucieude de Lucena Evangelista

Karlla Christine Araújo Souza

para o ensino médio, bem como a seus conteúdos. Esse currículo foi elaborado por professoras do ensino médio, estudantes e professores do curso de Licenciatura em Ciência Sociais da Universidade do Estado do Rio Grande do Norte, participantes do PIBID/UERN. Esse currículo vem sendo experimento nas atividades do PIBID. No contexto de uma "escola sem partido", uma iniciativa como essa não teria espaço, nem para sua livre elaboração, nem para sua implementação. Observamos que o título do projeto em si revela uma contradição: ele se propõe a fundar uma escola sem ideologia, mas partindo de uma ideologia institucionalizada, com o objetivo de cercear as vozes divergentes no interior da instituição escolar. Através dessa discussão pretendemos observar o ensino de Sociologia no contexto das transformações políticas que estão em curso no Brasil.

Palavras-chave: "Escola sem partido". Ensino de sociologia. Ideologia. PIBID.

\section{RESUMEN}

Este trabajo trata de una reflexión sobre el proyecto Escuela sin Partido desde la perspectiva de la enseñanza de Sociología en la enseñanza media. A pesar de que este proyecto aún no se haya concretado, su iniciativa ya demuestra un panorama preocupante para la educación en Brasil, ya que su propuesta no representa ninguna iniciativa para corregir los problemas que afectan a la educación en el país, en cambio, presenta propuestas que van en contra políticas como la valorización del profesor, que estaba siendo aplicada en los últimos años como una de las estrategias para mejorar la educación básica, promoviendo una fragilidad por criminalizar su libertad de pensamiento y de expresión, además de estimular la intolerancia. Nuestro objetivo es evaluar las probables implicaciones de este proyecto para el ejercicio del magisterio, lo cual se justifica por el impacto que puede provocar en la elaboración de los 
UMA ANÁLISE DOS FUNDAMENTOS DA ESCOLA SEM PARTIDO EM RELAÇÃO AO CURRÍCULO DE SOCIOLOGIA DO ENSINO MÉDIO

Guilherme Luiz Pereira Costa

Jucieude de Lucena Evangelista

Karlla Christine Araújo Souza

programas de la disciplina de Sociología, bien como la composición de los contenidos curriculares y su enfoque, y también la elaboración y la elección de materiales didácticos. La discusión para esta investigación se desarrolla a partir del análisis de los fundamentos del proyecto Escuela sin Partido, colocándolos en confrontación con los parámetros ( $P C N, D C N, O C N)$ que orientaron la elaboración de la propuesta del currículo de Sociología para la Enseñanza Media, así como sus contenidos. Tal currículo fue elaborado por profesores/as de la Enseñanza Media y del nivel Superior del Curso de Ciencias Sociales de la Universidade do Estado do Rio Grande do Norte (UERN), y los estudiantes de escuelas públicas donde actúa el Programa de Bolsas e Iniciação à Docência (PIBID) de esta misma institución superior, dentro del curso de Ciencias Sociales. A partir de este currículo y de la rutina escolar de estos profesores de la Red Básica de Educación, fueron elaboradas actividades por becarios del PIBID juntamente con los becarios Supervisores, que son profesores que actúan en la Enseñanza Media. Desde luego, concluimos que una iniciativa como ésta bajo el Escuela sin Partido no tendría espacio, ni para su libre elaboración, tan poco para su implementación. Incluso ya se observa, por el título, una contradicción: él se propone a fundar una escuela sin ideología, pero partiendo de una ideología institucionalizada, con el objetivo de cercenar las voces divergentes en el interior de la institución escolar. A través de esta discusión, pretendemos continuar nuestras observaciones en la enseñanza de Sociología en el contexto de las transformaciones políticas que están

en

curso

en

Brasil.

Palabras clave: "Escola sem partido". Enseñanza de Sociología. Ideología. PIBID. 
UMA ANÁLISE DOS FUNDAMENTOS DA ESCOLA SEM PARTIDO EM RELAÇÃO AO CURRÍCULO DE SOCIOLOGIA DO ENSINO MÉDIO

Guilherme Luiz Pereira Costa

Jucieude de Lucena Evangelista

Karlla Christine Araújo Souza

\section{INTRODUÇÃO}

Este trabalho trata de uma reflexão sobre o projeto Escola sem Partido a partir da perspectiva do ensino de Sociologia no ensino médio. Apesar desse projeto ainda não estar concretizado, sua iniciativa já demonstra uma perspectiva preocupante para a educação no Brasil. O projeto busca criminalizar os professores que não se limitam apenas a abordar os conteúdos curriculares e/ou a seguir as diretrizes prevista no projeto de lei, contribuindo para acentuar a desvalorização do magistério. O Escola Sem Partido caracteriza o professor que ensina a questionar a organização social como um falso educador, um doutrinador. Ele pressupõe o desvio de conduta em lugar de preveni-lo. Realiza um prejulgamento, pois considera o assédio, a intimidação ou a pressão ideológica como condutas frequentes sem que haja qualquer evidência empírica que confirme essa conduta.

Apesar do texto do projeto falar sobre a autonomia do aluno, os parlamentares que o idealizaram, não reconhecem esse aluno como sujeito capaz de desenvolver um pensamento crítico acerca de determinado assunto. Ele é considerado como mero ouvinte, vulnerável intelectualmente, sendo assim, facilmente manipulado pelos professores que supostamente ensinam ou insistem em "impor" suas ideologias.

Além de fragilizar o professor por conta da criminalização da sua liberdade de pensamento e de expressão, além de estimular a intolerância, planeja-se também monitorar os livros didáticos, provas e discutir sobre uma reforma nos currículos escolares e concursos. O professor não pode abordar nenhum tema que possa ir contra as convicções políticas e religiosas dos alunos ou de seus pais, pois no Escola Sem Partido está disposto: 


\section{UMA ANÁLISE DOS FUNDAMENTOS DA ESCOLA SEM PARTIDO EM RELAÇÃO AO CURRÍCULO DE SOCIOLOGIA DO ENSINO MÉDIO Guilherme Luiz Pereira Costa Jucieude de Lucena Evangelista Karlla Christine Araújo Souza}

Art. 3ํ. São vedadas, em sala de aula, a prática de doutrinação política e ideológica bem como a veiculação de conteúdos ou a realização de atividades que possam estar em conflito com as convicções religiosas ou morais dos pais ou responsáveis pelos estudantes. (PROJETO DE LEI № 867, 2015, p. 2)

Nosso trabalho foca, principalmente, nas aulas de Sociologia no Ensino Médio, pois consideramos que essa pode ser uma das disciplinas escolares mais afetadas. Nossa análise é feita com base numa proposta de currículo elaborada por bolsistas do PIBID e professores da Licenciatura em Ciência Sociais da Universidade do Estado do Rio Grande do Norte, além de professoras do ensino médio. Esse currículo está sendo aplicado de forma experimental nas escolas parceiras do programa. A partir desse currículo pretendemos analisar como a aprovação do Escola sem Partido pode implicar na limitação da abordagem de alguns conteúdos ou mesmo sua exclusão do currículo.

Partiremos do primeiro bimestre do primeiro ano do ensino médio, com o eixo "O homem como animal social". O tema inicial do currículo é, com certeza, um dos mais difíceis de serem debatidos, senso comum $x$ ciência. A simples tentativa de trabalhar esse assunto, certamente seria justificativa suficiente para encurralar o professor. Ao tratar das teorias da relação Indivíduo e Sociedade, o professor deverá ser bastante cuidadoso enquanto trabalha perspectivas clássicas de teóricos como Max Weber, Émile Durkheim e Karl Marx, pois trata-se de ideias divergentes acerca da realidade social. Principalmente quando problematiza a teoria marxista sobre uma suposta reorganização da sociedade, devido a constante crítica ao capitalismo e exaltação da revolução do proletariado.

No segundo bimestre, que tem como eixo "O homem como animal cultural" (no qual o currículo aborda os temas conceitos de cultura; etnocentrismo e relativismo cultural; diversidade cultural e identidade e diferença), todo o conjunto dos conteúdos pode ser comprometido, pois conhecer como os grupos sociais minoritários produzem culturas alternativas, 
UMA ANÁLISE DOS FUNDAMENTOS DA ESCOLA SEM PARTIDO EM RELAÇÃO AO CURRÍCULO DE SOCIOLOGIA DO ENSINO MÉDIO

Guilherme Luiz Pereira Costa

Jucieude de Lucena Evangelista

Karlla Christine Araújo Souza

refletir sobre os diferentes conceitos de cultura e definir o conceito de etnocentrismo, podemos assim pensar que são assuntos que não terão oportunidade para o debate na escola.

O projeto como tal, que foi concebido por autores que se dizem preocupados com o direito à educação e à cultura, no entanto, o seu conteúdo não expressa a consideração da liberdade de pensamento e 0 desenvolvimento do educando mas, ao contrário, sua domesticação. No fundo, o que o projeto transparece é a preocupação com a preparação para o mercado de trabalho e uma educação orientada por valores da familia tradicional brasileira. Escola Sem partido não é uma proposta ou a solução, mas é mais um fator político. Representa uma ideologia cujo projeto político pode agravar os problemas da educação do Brasil.

\section{SOBRE OS CONTEÚDOS DO CURRÍCULO DE SOCIOLOGIA PARA O ENSINO MÉDIO DO RIO GRANDE DO NORTE}

O contato com a Sociologia na escola e as outras disciplinas das ciências sociais, como História, Geografia e Filosofia. Levando em conta o professor, sua formação e didática, reforça no aluno novas formas de ver o mundo; capacitando-o para o entendimento e questionamento dos fenômenos e das construções sociais, ou seja, mostrando o desenvolvimento do pensamento crítico.

Usando a proposta de currículo de Sociologia para o Ensino Médio elaborado pelo grupo do PIBID/UERN e os conhecimentos de Sociologia, Antropologia e Política de acordo com os parâmetros Curriculares Nacionais, discutiremos sobre alguns eixos e temas que sofrerão implicações ao serem debatidos em sala aula, partindo do que está disposto no Escola Sem Partido: 


\section{UMA ANÁLISE DOS FUNDAMENTOS DA ESCOLA SEM PARTIDO EM RELAÇÃO AO CURRÍCULO DE SOCIOLOGIA DO ENSINO MÉDIO Guilherme Luiz Pereira Costa Jucieude de Lucena Evangelista Karlla Christine Araújo Souza}

O objetivo do currículo de Sociologia para o ensino médio é que ele apresente uma diversidade de conteúdos que instigue 0 aluno à pesquisa e aprofundamento dos mesmos, buscando assim tornar indivíduos críticos, que saibam analisar o mundo ao seu redor e chegar a conclusões sobre o que seria melhor para ele e para a comunidade a que pertence. $O$ objetivo deste caderno refere-se a uma apresentação formal da proposta de currículo para o ensino de Sociologia do PIBID Ciências Sociais/UERN/Campus Central para o Estado do Rio Grande do Norte. Dividimos o currículo por bimestre, sendo quatro bimestres para cada ano letivo que giram em torno de eixos temáticos das diferentes áreas das Ciências Sociais, propondo as temáticas juntamente com um material de apoio, como literatura, filmes, documentários, resultados de pesquisas atuais e os objetivos de cada conteúdo. Assim, pensamos o currículo de forma dinâmica, aberta e inovadora a fim de levar ao aluno os diversos olhares sobre os conceitos, teorias e temas da Sociologia e o estranhamento que 0 olhar científico pode proporcionar. Para tanto, pensamos o ensino de sociologia como uma ferramenta a qual o jovem possa utilizar para entender o funcionamento da sociedade em que vive, sendo capaz de identificar as ações e relações sociais por meio dos significados construídos individual e coletivamente. Este currículo foi construído através de pesquisa bibliográfica, de discussão coletiva nos encontros semanais do PIBID Ciências Sociais com colaboração das Professoras Doutoras Ana Morais e Andréa Linhares, ambas do Departamento de Ciências Sociais e Política da Universidade do Estado do Rio Grande do Norte, com a contribuição das supervisoras do PIBID Ciências Sociais e professoras de Sociologia das Escolas Estaduais Centro de Educação Integrado Eliseu Viana, Diram Amaral, Governador Dix-Sept Rosado e Moreira Dias, com a realização de pesquisa empírica realizada com os alunos das respectivas escolas, e estudo realizado com a colaboração da Profa. Ms. Márcia Betânia de Oliveira acerca da Teoria Pós-estrutralista do Currículo. Vale salientar que a primeira grande conquista desta proposta foi sua inclusão no Projeto Político Pedagógico da Escola Estadual Diram Amaral. O próximo passo deve ser colocar em prática, por meio de minicurso para dinamização do currículo ministrado por Anchieta Filho (SEEC/Fortaleza/CE) e das atividades do PIBID Ciências Sociais, todas os conteúdos aqui propostos a fim elaborar um caderno completo com a didática de cada aula experimentada. (Currículo de sociologia para o Rio Grande do Norte, 2014)

Quando o aluno é inserido na escola, deve-se considerar que ele já carrega consigo uma bagagem de concepções produzidas em seu meio social, mediante a vivência histórica. O professor não pode trabalhar com seus alunos supondo que estes não conhecem nada. O senso comum está ligado aos sistemas de crenças e cultura do sujeito. É um conhecimento que não é dado como verdade universal, variando de acordo com a cultura de cada indivíduo. 


\title{
UMA ANÁLISE DOS FUNDAMENTOS DA ESCOLA SEM PARTIDO EM RELAÇÃO AO CURRÍCULO DE SOCIOLOGIA DO ENSINO MÉDIO Guilherme Luiz Pereira Costa Jucieude de Lucena Evangelista Karlla Christine Araújo Souza
}

Desde cedo o sujeito internaliza conceitos que são desenvolvidos e aprendidos na interação com o espaço social. Mesmo aquilo que caracterizamos como atitudes individuais, é fruto da relação com outros seres sociais.

\begin{abstract}
Para Vygotsky, não é suficiente ter todo o aparato biológico da espécie para realizar uma tarefa se o indivíduo não participa de ambientes e práticas específicas que propiciem esta aprendizagem. Não podemos pensar que a criança vai se desenvolver com o tempo, pois esta não tem, por si só, instrumentos para percorrer sozinha o caminho do desenvolvimento, que dependerá das suas aprendizagens mediante as experiências a que foi exposta. Neste modelo, o sujeito - no caso, a criança - é reconhecida como ser pensante, capaz de vincular sua ação à representação de mundo que constitui sua cultura, sendo a escola um espaço e um tempo onde este processo é vivenciado, onde o processo de ensinoaprendizagem envolve diretamente a interação entre sujeitos (VYGOTSKY apud RABELLO; PASSOS, 2016, p. 5).
\end{abstract}

Em uma aula que reforce a fragilidade do senso comum e explique a necessidade de um conhecimento mais aprofundado, que se caracterize por métodos de investigação e experimento para se chegar à uma determinada conclusão, o professor pode ser acusado de ferir ideologicamente o aluno se trabalhar - numa aula sobre ciências e senso comum, por exemplo, um dos conteúdos introdutório do currículo elaborado pelo PIBID - algum exemplo que possa ser contrário às superstições que $\mathrm{o}$ aluno aprendeu com a familia $\mathrm{e}$ considera como verdade. Podemos citar, por exemplo, achar que cortar os cabelos na lua crescente faz com que os cabelos cresçam mais rápido; passar debaixo de uma escada dá azar ou se recusar a tomar leite logo após chupar manga por acreditar que essa combinação de alimentos não fará bem para o organismo e poderá levar à morte. O Escola Sem Partido dispõe: "O Professor respeitará o direito dos pais a que seus filhos recebam a educação moral que esteja de acordo com suas próprias convicções." (PROJETO DE LEI N.․․ 867, DE 2015, P. 5)

Em contrapartida, os Parâmetros Curriculares Nacionais reconhecem a importância de realizar um reforço para entender a realidade social, ampliando 


\title{
UMA ANÁLISE DOS FUNDAMENTOS DA ESCOLA SEM PARTIDO EM RELAÇÃO AO CURRÍCULO DE SOCIOLOGIA DO ENSINO MÉDIO Guilherme Luiz Pereira Costa Jucieude de Lucena Evangelista Karlla Christine Araújo Souza
}

a "visão de mundo" do aluno, identificando, analisando e comparando os diferentes discursos sobre a realidade:

\begin{abstract}
Cabe ressaltar que a reflexão empreendida pelo sociólogo como interpretação da realidade social não deve acontecer no mesmo nível de apreensão do senso comum ${ }^{1}$, porque as questões são construídas em termos da explicação, pela mediação teóricometodológica de natureza própria, por ser um tipo de conhecimento sistematizado da realidade social, consubstanciado por um conjunto pluriparadigmático de conceitos e categorias" (Parâmetros Curriculares Nacionais Ensino Médio, p. 38).
\end{abstract}

É típico de nossa sociedade imaginar a cultura indígena como uma cultura inferior e pouco complexa. Crescemos em um contexto que caracterizava o índio como o "ser" preguiçoso que vive dentro do mato e que não gosta de trabalhar. Nos foi dada uma interpretação de que ele é inferior ao homem branco porque vive de uma maneira "ultrapassada", não civilizada. $\mathrm{O}$ trabalho das ciências sociais no Ensino Médio, segundo os Parâmetros Curriculares Nacionais, é desenvolver no aluno a habilidade de:

Compreender e valorizar as diferentes manifestações culturais de etnias e segmentos sociais, agindo de modo a preservar o direito à diversidade, enquanto princípio estético, político e ético que supera conflitos e tensões do mundo atual." (PARÂMETROS CURRICULARES NACIONAIS - ENSINO MÉDIO, p. 43).

Para abordar as questões étnicas, por exemplo, o professor pode discutir nas aulas a questão das diferenças culturais e visão de mundo, trabalhando conceitos básicos antropológicos como cultura, etnocentrismo, alteridade, relativismo, etc. Capacitando o aluno para compreender a relação entre o "eu" e o "outro", tornando-o assim, capaz de conviver com a diferença e entender a necessidade de respeitar a cultura alheia. No caso do índio, é preciso conduzir o aluno a rever a noção de organização social desses povos, superando as ideias equivocadas. Não significa que o indígena seja

${ }^{1}$ Grifo do autor

Inter-Legere - Revista de Pós-Graduação em Ciências Sociais da UFRN Natal RN, ISSN 1982-1662, no 20, jan./jun. de 2017 


\section{UMA ANÁLISE DOS FUNDAMENTOS DA ESCOLA SEM PARTIDO EM RELAÇÃO AO CURRÍCULO DE SOCIOLOGIA DO ENSINO MÉDIO Guilherme Luiz Pereira Costa Jucieude de Lucena Evangelista Karlla Christine Araújo Souza}

preguiçoso, ele trabalha apenas o suficiente para suprir suas necessidades e as da coletividade.

E uma aula sobre o conteúdo de Etnocentrismo e Relativismo cultural, ao tratar da necessidade e da dificuldade de pensarmos a diferença, 0 professor pode estar sujeito a ser denunciado e enquadrado na lei, caso algum aluno entenda que, ao falar em relativizar uma sociedade ou uma religião que não seja a sua e de sua família, o professor pode estar tentando dissuadi-lo de seus valores e práticas sociais. Isto, segundo a lei, poderá ser considerado "bullying ideológico" dentro da sala de aula. Quanto ao trabalho do professor, o texto do Escola Sem Partido dispõe:

"Art. 4․ No exercício de suas funções, o professor:

I - não se aproveitará da audiência cativa dos alunos, com o objetivo de cooptá-los para esta ou aquela corrente política, ideológica ou partidária;

II - não favorecerá nem prejudicará os alunos em razão de suas convicções políticas, ideológicas, morais ou religiosas, ou da falta delas;

III - não fará propaganda político-partidária em sala de aula nem incitará seus alunos a participar de manifestações, atos públicos e passeatas;

IV - ao tratar de questões políticas, sócio-culturais e econômicas, apresentará aos alunos, de forma justa, as principais versões, teorias, opiniões e perspectivas concorrentes a respeito;

V - respeitará o direito dos pais a que seus filhos recebam a educação moral que esteja de acordo com suas próprias convicções;

VI - não permitirá que os direitos assegurados nos itens anteriores sejam violados pela ação de terceiros, dentro da sala de aula." (p. 4) 
UMA ANÁLISE DOS FUNDAMENTOS DA ESCOLA SEM PARTIDO EM RELAÇÃO AO CURRÍCULO DE SOCIOLOGIA DO ENSINO MÉDIO

Guilherme Luiz Pereira Costa

Jucieude de Lucena Evangelista

Karlla Christine Araújo Souza

\section{SOBRE O ESCOLA SEM PARTIDO E SUA IDEOLOGIA}

A proposta do Escola Sem Partido não é tão nova. Desde 2004 discutese sobre ela, mas somente há pouco tempo se tornou um Projeto de Lei (Projeto de Lei: 867/2015) e foi apresentado para apreciação do Congresso Nacional. Ele é de autoria do Advogado Miguel Nagib e apresentado à Câmara dos Deputados pelo deputado federal Izalci Lucas Ferreira (PSDB-DF). Seus idealizadores afirmam que o projeto surge na necessidade de defender os estudantes na escola, pois a grande maioria dos professores pregam uma ideologia considerada danosa dentro de sala de aula.

O Escola Sem Partido foca principalmente em combater a "doutrinação ideológica" trazendo a intervenção da neutralidade do ensino e ditando como o professor deve se comportar. Baseados na ideia de que os professores ensinam uma visão tendenciosa da realidade, e assim prejudicam ideologicamente os alunos, eles entendem que cabe somente aos pais decidirem o que os seus filhos devem ou não aprender. Consideram o suposto engajamento político-ideológico do professor e o material didático trabalhado como um dos graves problemas da educação brasileira. No Projeto de Lei: 867/2015 está escrito:

É fato notório que professores e autores de livros didáticos vêm-se utilizando de suas aulas e de suas obras para tentar obter a adesão dos estudantes a determinadas correntes políticas e ideológicas; e para fazer com que eles adotem padrões de julgamento e de conduta moral - especialmente moral sexual - incompatíveis com os que thes são ensinados por seus pais ou responsáveis. (PROJETO DE LEI N 867,2015, p. 5).

Esse projeto de Lei tem dividido opiniões, principalmente entre os próprios professores. Muitos entendem que no contexto de uma "escola sem partido", a suposta neutralidade no ensino não teria espaço, nem para sua livre elaboração, nem para sua implementação. Observamos que o título do projeto 
UMA ANÁLISE DOS FUNDAMENTOS DA ESCOLA SEM PARTIDO EM RELAÇÃO AO CURRÍCULO DE SOCIOLOGIA DO ENSINO MÉDIO

Guilherme Luiz Pereira Costa

Jucieude de Lucena Evangelista

Karlla Christine Araújo Souza

em si revela uma contradição: ele se propõe a fundar uma escola sem ideologia, mas partindo de uma ideologia institucionalizada, com o objetivo de cercear as vozes divergentes no interior da instituição escolar.

O que realmente está em jogo não é a preocupação com a classe estudantil, mas enfrentar as ideias de um projeto político que se manteve no poder democraticamente, sendo endossado pelo voto popular em quatro eleições consecutivas. Os opositores do Escola sem Partido afirmam que a intenção ao criar um aparato jurídico para "amordaçar" e punir os profissionais do ensino, é uma maneira de atacar as ideias ditas de esquerda. O deputado Izalci Ferreira (PSDB-DF) acredita que realmente o problema da alienação partidária, que é ensinada nas escolas brasileiras, não é devido a todos os partidos, mas é responsabilidade do partido que estava no poder.

Miguel Nagib diz que sua proposição é de caráter apartidário, mas se contextualizarmos seus argumentos, eles estão em consonância com as mudanças políticas no país e com a tomada de poder pelos partidos de direita. Estes têm levado à frente, não só seu projeto de tomada de poder, mas de inviabilização das ideias e das correntes políticas contrárias. O Escola sem Partido se insere num conjunto de ações que visam atingir principalmente o Partido dos Trabalhadores, que governou o Brasil de janeiro de 2002 até abril de 2016.

A bancada de parlamentares que diz reconhecer que o professor ensina somente o que quer, mesmo sendo dever dele debater sobre todos os temas, é a mesma bancada que barrou a discussão sobre relação de gênero na escola. Nagib afirmou no programa Sala Debate, no Canal Futura, que o professor não pode ter liberdade de expressão, deve limitar-se apenas a transmitir o conteúdo e que estimular a criticidade do aluno não é papel do docente.

É preciso entender que o aluno vive em sociedade. Ele se encontra diariamente em confronto com problemas que precisam de resposta. As 


\title{
UMA ANÁLISE DOS FUNDAMENTOS DA ESCOLA SEM PARTIDO EM RELAÇÃO AO CURRÍCULO DE SOCIOLOGIA DO ENSINO MÉDIO Guilherme Luiz Pereira Costa Jucieude de Lucena Evangelista Karlla Christine Araújo Souza
}

questões sociais não são respondidas sempre de forma imediata ou pragmática. $\mathrm{O}$ mundo social pede reflexão. $\mathrm{O}$ estudante tem uma construção social que vai além dos limites da escola. De acordo com lanni:

\begin{abstract}
O problema preliminar, que se coloca no trabalho do professor de Ciências Sociais, surge no âmbito de $1^{\circ}$ e $2^{\circ}$ graus e, também, no $3^{\circ}$ grau. Como mobilizar o conhecimento de que o aluno já dispõe e, ao mesmo tempo, levar ao aluno novos conhecimentos? Seria ilusório um professor trabalhar com seus alunos imaginado que eles não sabem nada ou que nada conhecem. Não! Através do rádio, da televisão, do jornal, da família e de outros meios, eles já ouviram falar sobre diferentes temas que têm a ver com o campo das Ciências Sociais e que estão no universo de todos, inclusive das crianças [...]"(IANNI, 2011, p. 328)
\end{abstract}

Não estamos aqui refletindo acerca da necessidade de defender professores "doutrinadores". Não reconhecemos essa qualidade como atributo do professor. Entendemos que o projeto, ao contrário do que se propõe, é explicitamente partidarizado e ideológico na sua concepção. Ele não apenas limita o desempenho do professor, mas também impede um diálogo democrático dentro da sala de aula, que é o lugar onde o professor disponibiliza os meios do saber à disposição de todos. Por mais que tente, sabemos, ninguém jamais é totalmente neutro. Mas a neutralidade não é uma necessidade na educação, o necessário é a abertura do pensamento para o conhecimento pelo diálogo e pela tolerância. Se há algo de doutrinário a ser evitado na escola, é sem dúvida o Escola sem Partido.

\section{REFERÊNCIAS}

ARENDT, Hannah. A crise na educação. In: Entre o passado e o futuro. Tradução de Mauro W. Barbosa. São Paulo: Perspectiva, 2011.

BRASIL. Ministério da Educação. Parâmetros Curriculares Nacionais (Ensino Médio). Ciências Humanas e suas Tecnologias. Brasilia: MEC/SEF, 1999. 
UMA ANÁLISE DOS FUNDAMENTOS DA ESCOLA SEM PARTIDO EM RELAÇÃO AO CURRÍCULO DE SOCIOLOGIA DO ENSINO MÉDIO Guilherme Luiz Pereira Costa Jucieude de Lucena Evangelista Karlla Christine Araújo Souza

IANNI, O. O ensino das Ciências Sociais no $1^{\circ}$ e $2^{\circ}$ graus. Campinas: Cad. Cedes. 2011

LOPES, E. J. O curso de Ciências Sociais também é como um lago. Londrina: Revista Mediações. 2001.

MORAES, A. C. O que temos de aprender para ensinar Ciências Sociais? Natal-RN: Cronos. 2007.

NAGIB, Miguel. PENA. Fernando de Araújo. Escola sem Partido. Entrevista concedida a José Brito Cunha. Disponível em:

$<$ https://www. youtube.com/watch?v=J2v7PA1RNqk> Acesso em 01 nov. 2016.

RABELLO, E. T e PASSOS, J. S. Vygostsky e o desenvolvimento humano. Disponível em <http://www.joseoliveira.com > Acesso em 30 out.2016.

ROCHA, E. P. G. O que é etnocentrismo. São Paulo. Editora Brasiliense. 1988.

SARANDY, F. M. S. Reflexões acerca do sentido da Sociologia no Ensino Médio. Revista Espaço Acadêmico. 2001

Projeto Escola Sem partido. PROJETO DE LEI N. 867, DE 2015. Câmara dos Deputados. Izalci Lucas Ferreira. 2015. Disponível em: $<$ http://escolasempartido.org/component/content/article/2-uncategorised/484anteprojeto-de-lei-estadual-e-minuta-de-justificativa> Acesso em 01 nov 2016.

VIGOSTSKY, L. S. Pensamento e linguagem. Rio de Janeiro: Martins Fontes. 1998

1996

A formação social da mente. Rio de Janeiro: Martins Fontes.

WEBER, M. Ciência e Política: duas vocações. São Paulo: Martin Claret. 2006 